\title{
A exposição (Darstellung) poética na metafísica do belo de Schopenhauer
}

\author{
The poetic exposition (Darstellung) in Schopenhauer's Metaphysics of the \\ beautiful
}

\author{
Cláudia Assunpção Dias \\ Mestranda em Filosofia pela Universidade Federal do Paraná (UFPR) \\ E-mail: claudia.assunpcao@gmail.com
}

\begin{abstract}
Resumo: Para Schopenhauer, a arte poética apresenta uma natureza diferenciada em relação às outras artes no que tange aos meios estabelecidos pelo filósofo para a sua exposição (Darstellung) e à relação entre tal exposição e a intuição genial que a precede. Afinal, como admitir que para a poesia também vale a concepção de que, sendo essencialmente intuitivas, as Ideias seriam por ela expressas de forma límpida e vivaz, se o material com o qual o poeta trabalha são conceitos abstratos? Ou seja, como conciliar esta condição da arte poética com o pressuposto da metafísica do belo schopenhaueriana segundo o qual "o conhecimento da Ideia é necessariamente intuitivo, não abstrato"? Com o presente artigo, pretendemos evidenciar como Schopenhauer, logo no início do $\S 51$ do Tomo I de 0 mundo como vontade e como representação, se esforça para indicar algumas saídas para a questão. A principal delas é a defesa de que o poeta só conseguiria fazer o ouvinte intuir as Ideias da vida com a ajuda de sua [do ouvinte] própria fantasia. 0 filósofo apresenta também outras observações sobre o modo com que os conceitos teriam de ser reunidos para que a fantasia do ouvinte seja posta em movimento, assim como sobre o ritmo, a rima etc., questões de exposição poética que aparecem ainda mais especificadas nas Preleções sobre a Metafísica do belo (1820).
\end{abstract}

Abstract: For Schopenhauer, poetic art presents a differentiated nature when it comes to its relations to other arts, not only in the matter of ways established by the philosopher for its representation (Darstellung) and of its relations between representation and the genial intuition that preceds it. After all, how admit that for poetry also worth the conception that, being essentially intuitive, the Ideas would be by it expressed in a clear and lively form, if the materials that the poet works on are nothing but abstract concepts? In other words, how to conciliate this poetic arts' condition with the assumption from the Schopenhauer's Metaphysics of Beauty, according to which "knowledge of the Ideas is necessarily knowledge through perception, and is not abstract"? The present article intends to show how Schopenhauer, in the beggining of $\S 51$ from the first volume of The World as Will and Representation, put an effort to indicate some alternatives for the question. The main one is a defense that the poet could only make his reader intuit the Ideas of life with some help from the reader's own fantasy. The philosopher also presentes others reflections about the way that concepts would have to be combined for that the reader's fantasy could be set in motion, as well as about the rhythm, the rhyme etc., questions of poetic exposition that are more specified in the Lessons about Metaphysics of Beauty (1820). 
Palavras-chave: Poesia; Exposição; Fantasia. Keywords: Poetry; Exposition; Fantasy. 
$\mathrm{P}$ ara fins de elucidação das questões de natureza crítica que exporemos nos tópicos a seguir, consideremos, de início, alguns pressupostos básicos da filosofia schopenhaueriana: 1) Schopenhauer é conhecido por ter atribuído um papel central às artes em sua metafísica imanente da vontade, mais especificamente no âmago do que denominou de metafísica do belo; 2) o filósofo toma o em-si do mundo (que, segundo ele, corresponderia de alguma forma à noção de coisaem-si de Kant) como uma vontade irracional e desprovida de finalidade, que não cessa de se manifestar em variados graus no mundo fenomênico; 3) no entanto - numa assimilação de Platão ${ }^{1}$-, Schopenhauer entende que antes de se espraiar na diversidade dos fenômenos da representação, essa vontade sai de sua cegueira originária mediante Ideias, arquétipos eternos das coisas do mundo. A manifestação da vontade como conteúdo essencial do mundo dar-se-ia por meio de Ideias como atos originários da vontade (ursprüngliche Willensakte), uma série de graus ou espécies, que vão desde o inorgânico até o ser humano consciente. Tratam-se das Ideias platônicas mesmo, tomadas pelo filósofo alemão como formas

imutáveis, imperecíveis e que nunca devêm de todas as coisas que nascem, mudam e perecem. Exatamente elas são os nossos graus de objetivação da vontade, ou seja, todas as espécies determinadas dos reinos orgânico e inorgânico, as formas originárias e índoles imutáveis de todos os corpos naturais, também de todas as forças naturais que se manifestam segundo leis naturais $[\ldots]^{2}$

Desse modo, as Ideias, diferentemente dos fenômenos com sua pluralização, são entendidas aqui como representações independentes do princípio de razão. Ou seja, é ainda a coisa-em-si, apenas na forma mais geral de sua representação; um objeto para um sujeito que, no entanto, ainda não está submetido às condições temporais, espaciais e causais. 0 sujeito que atua para apreender tais Ideias é puro e indiviso, um correlato subjetivo da própria Ideia que consegue intuir os arquétipos eternos do mundo de forma límpida, capacidade que Schopenhauer reconhecerá na figura do gênio como oposta ao

\footnotetext{
${ }^{1}$ Embora, como sabemos, o conceito schopenhaueriano de Ideia apresente muitas semelhanças com a Ideia platônica - Schopenhauer o definiu como idêntico à Ideia platônica -, podemos observar algumas diferenças: não existe, por exemplo, uma Ideia propriamente dita de matéria e nem de artefatos em Schopenhauer, mas Ideias de materiais ou qualidades da matéria. Portanto, não existe a Ideia de cadeira, por exemplo, mas o material de que é produzida a cadeira, como a madeira, o ferro etc (Cf. SCHOPENHAUER, A. MB, p. 107).

2 SCHOPENHAUER, A. MB, p. 30.

A exposição (Darstellung) poética na metafísica do belo de Schopenhauer
} 
do mero indivíduo.

A natureza dos reinos mineral, vegetal, animal e humano apresenta-se como meio de afirmação da vontade de vida (Willens zum Leben), esta que se expressa no querer e nos desejos de cada natureza individual e que, por ser tomada como um princípio cego e incessante, gera necessariamente dor e sofrimento por toda parte. As Ideias, ao pluralizarem-se numa infinidade de fenômenos, precisam de matéria, motivo pelo qual surge uma disputa e uma luta sem fim de todos os indivíduos. 0 sofrimento é, então, inerente a esse processo porque a vontade, que não sabe o que quer, é autodiscordante e geradora de disputas e querelas, com o que se justifica uma das máximas pelas quais a filosofia schopenhaueriana é conhecida: Alles Leben ist Leiden (toda vida é sofrimento).

Diante disso, a metafísica do belo seria uma instância que, se não possibilitaria a negação da vontade propriamente dita, ao menos potencializaria uma neutralização do sofrimento, dado que o belo se apresenta como um conhecimento que fornece um acesso privilegiado às Ideias e, assim, provoca em quem o frui um apaziguamento do querer ${ }^{3}$. A fruição do belo, que pauta um "estado estético" nessa filosofia, é possível tanto na natureza quanto na arte, mas neste último caso há o papel central do gênio como possibilitador da comunicação do belo aos outros por meio de sua obra de arte. A arte é definida como "exposição de Ideias", um modo de consideração das coisas independente do princípio de razão (o que a diferencia da ciência), um tipo de conhecimento cristalino dos graus de objetivação da vontade. E ao gênio, uma faculdade comum a todos em maior ou menor grau, cabe intuir o essencial do mundo, o conteúdo perene e verdadeiro dos objetos, ou seja, as próprias Ideias, e expor suas verdades numa obra artística. 0 gênio primeiro intui na natureza o que depois expõe aos outros. Já ao expectador caberia fruir essa exposição, o que também lhe exigiria um certo grau de genialidade. Assim, o conhecimento do belo é tido por Schopenhauer como "o conhecimento mais profundo e verdadeiro da essência propriamente dita do mundo"4. Trata-se de um conhecimento que não pode ser apreendido abstratamente, mas só intuitivamente; ele não pode ser comunicado por conceitos ou doutrinas, mas apenas por obras artísticas, assim como a verdade da intuição estética é acessada pelo puro sujeito do conhecimento, em alguma medida destituído de vontade e de sofrimentos e que consegue intuir os arquétipos do mundo não turvados pela realidade fenomênica. Nesse sentido, a arte desencarceraria o

\footnotetext{
${ }^{3}$ Sobre a possível abertura à tese da negação da vontade contida na contemplação do belo, cf. BRUM, J. T. $O$ pessimismo e suas vontades, p. 116.

${ }^{4}$ SCHOPENHAUER, A. MB, p. 26.

A exposição (Darstellung) poética na metafísica do belo de Schopenhauer
} 
objeto de suas relações, tornando-o um representante do todo, da sua espécie; já o indivíduo, tornar-se-ia puro sujeito do conhecimento.

\section{A exposição poética na metafísica do belo}

Como sabemos, Schopenhauer formulou também na sua metafísica do belo uma hierarquia das artes, classificando-as de acordo com seus objetos que, por sua vez, seguem os graus de objetivação da vontade. Assim, à arquitetura caberá comunicar em suas construções as Ideias mais inferiores da vontade, as qualidades da matéria (rigidez, reação à luz, gravidade etc); à jardinagem e à pintura paisagística, as Ideias do reino vegetal; à escultura e à pintura de animais, superadas pela escultura e pela pintura humanas, caberá transmitir as Ideias dos reinos animal e humano, mesmo que de forma restrita, pois não conseguem abranger movimentos e cadeias de ações. Por fim, no ápice da hierarquia, encontra-se a poesia ${ }^{5}$, expositora da Ideia na qual a vontade atinge a sua mais elevada objetivação, o homem. Por permitir com seus conceitos uma dinâmica narrativa de cadeias e séries de ações e semblantes, a poesia supera as artes plásticas, sendo a tragédia o seu modelo superior, dado que expõe a humanidade em seu aspecto mais terrível e autodiscordante.

Cabe salientar, então, que Schopenhauer admite efetivamente a superioridade de uma arte sobre outra apenas na esfera da exposição (Darstellung), ou seja, não haveria uma hierarquia das artes no que respeita ao momento da intuição estética, visto que gênio e objeto da intuição seriam unos. Nesse sentido, o que determina a superioridade de uma arte em relação à outra é a Ideia que cada arte expõe. De acordo com o filósofo,

sabemos que todas as artes têm um objetivo, a exposição das Ideias: sua diferença mais essencial reside meramente apenas no grau de objetivação da Vontade - a Ideia - que será exposto, com o que também se determina o material da exposiçãó6.

\footnotetext{
${ }^{5}$ Consideremos que a música é tomada por Schopenhauer como a arte mais excelsa de todas, classificada no ápice da hierarquia, mas que, justamente por isso, exige uma abordagem diferenciada em relação às demais, dado que não é tida como cópia ou repetição de alguma Ideia das coisas do mundo. Ao invés disso, ela é tomada como a própria "linguagem universal" da coisa-em-si, uma vez que reproduz todos os graus de objetidade da vontade, o que a torna análoga ao próprio mundo. À diferença das demais artes, a música, se correta e perfeitamente executada, exprimiria o próprio mundo em seus variados tons.
}

${ }^{6}$ SCHOPENHAUER, A. MVR I, § 51, p. 291.

A exposição (Darstellung) poética na metafísica do belo de Schopenhauer 
Dessa maneira, tanto a intuição estética (ästhetische Anschauung) quanto a exposição (Darstellung) são representações. Porém, a primeira trabalha com Ideias independentes do princípio de razão, enquanto a segunda com representações submetidas a tal princípio. Neste caso, Schopenhauer teria admitido uma hierarquia das artes apenas na esfera da exposição, tendo em vista que o material com o qual cada arte se ocupa está submetido à Ideia que expõe. Por exemplo, a arquitetura não foi situada por Schopenhauer na base da pirâmide porque o material com o qual trabalha é a pedra, mas porque ela expõe as Ideias mais gerais da matéria (rigidez, gravidade e resistência) que indicam um grau inferior de objetivação da vontade. Do mesmo modo, a jardinagem é considerada superior à arquitetura porque expõe Ideias do reino vegetal, que são superiores às do reino mineral. Em outras palavras, trata-se de uma gradação que se dá no âmbito da afirmação, ou melhor, da objetivação da Vontade, a qual pode ser visualizada a partir de uma pirâmide, cuja base representaria o inorgânico, as partes intermediárias os vegetais e os animais, e o ápice, o homem7.

Neste ínterim, a arte poética, segundo Schopenhauer, apresenta uma superioridade em relação às outras artes porque expõe a Ideia de Humanidade não apenas por meio das simples formas e afeições do homem - como fazem a pintura e a escultura -, mas por meio de uma sequência de ações, pensamentos e afetos que dele se seguem. Além disso, devido à universalidade do material de que se serve a poesia para expor as Ideias, os conceitos, a extensão de seu campo de exposição é muita vasta. Ou seja, a poesia expõe toda a natureza, as Ideias de todos os graus, seja pela descrição ou narração, seja expondo imediatamente de maneira dramática. No entanto, a arte poética é superior a todas as outras apenas quando comunica a Ideia de ser humano com seus movimentos e ações ${ }^{8}$.

Ora, o intento maior do presente artigo advém justamente da natureza diferenciada da arte poética frente às outras artes no que tange às condições e aos meios estabelecidos por Schopenhauer para a sua exposição (Darstellung), mas também no que respeita à relação entre tal exposição e a intuição genial que a precede. A questão pode ser assim formulada: como admitir que para a poesia também vale a concepção de que, sendo essencialmente intuitivas, as Ideias seriam por ela expressas de forma límpida e vivaz, se o material com o qual o poeta trabalha são conceitos abstratos? Ou seja, como

${ }^{7}$ Cf. BARBOZA, J. A metafísica do belo de Arthur Schopenhauer, p. 121.

${ }^{8}$ Cf. SCHOPENHAUER, A. MVR I, § 51, p. 282.

A exposição (Darstellung) poética na metafísica do belo de Schopenhauer 
conciliar esta condição da arte poética com o pressuposto da metafísica do belo schopenhaueriana segundo o qual "o conhecimento da Ideia é necessariamente intuitivo, não abstrato"9? Vejamos.

\section{Genialidade e fantasia na arte da exposição poética}

No parágrafo 36 do Tomo I de 0 mundo como vontade e como representação, Schopenhauer define alguns dos conceitos centrais de sua metafísica do belo, introduzindo a seguinte questão:

Qual modo de conhecimento considera unicamente o essencial propriamente dito do mundo, alheio e independente de toda relação, o conteúdo verdadeiro das aparências, não submetido a mudança alguma e, por conseguinte, conhecido com igual verdade por todo o tempo, numa palavra, as IDEIAS, que são a objetidade imediata e adequada da coisa em si, a vontade? - Resposta: é a ARTE, a obra do gênio ${ }^{10}$.

Nesse sentido, a arte, para Schopenhauer, repete as Ideias eternas apreendidas por pura contemplação, que apresentam o essencial e permanente de todos os fenômenos ou aparências do mundo. A arte teria como função sui generis o conhecimento das Ideias, e como único objetivo a comunicação do mesmo. Neste caso, o conhecimento do gênio seria limitado às Ideias dos objetos afetivamente presentes à sua pessoa. No entanto, de que modo o gênio poderia nos comunicar o conhecimento das Ideias de forma límpida e vivaz se os objetos efetivos são quase sempre apenas exemplares bastante imperfeitos em relação à Ideia que neles se expõe? Em vista disso, sabemos que Schopenhauer defende que o gênio precisa da fantasia para ver nos objetos não o que a natureza formou efetivamente, mas o que se esforçava por formar. Portanto, a fantasia amplia o círculo de apreensão do gênio para além dos objetos que se apresentam na efetividade à sua pessoa, tanto em qualidade quanto em quantidade.

Retomemos, então, nossa questão a respeito da poesia, ou seja, de como o poeta (gênio) expressaria as Ideias de forma límpida e vivaz, se o material com o qual trabalha são conceitos abstratos. Logo no início do $§ 51$ do Tomo I de $O$ mundo como vontade e como representação, dedicado à poesia, Schopenhauer tem presente essa questão e

\footnotetext{
${ }^{9}$ Idem, § 36, p. 215.

10 Idem, p. 213.

A exposição (Darstellung) poética na metafísica do belo de Schopenhauer
} 
parece esforçar-se para indicar algumas saídas: a principal delas é a defesa de que, dado que "na poesia apenas conceitos abstratos são comunicados imediatamente por palavras"11, o poeta só conseguiria fazer o ouvinte intuir as Ideias da vida "com a ajuda de sua [do ouvinte] própria fantasia"12. Desse modo, somos levados a pensar que assim como Schopenhauer pressupõe na metafísica do belo certa quota de genialidade, tanto na criação quanto na fruição da obra de arte, também e principalmente no caso da arte poética seria necessária certa quota de fantasia tanto por parte do poeta (gênio) quanto por parte do leitor (ouvinte), mas no primeiro com muito mais vigor. Em outras palavras, é também por meio de sua própria fantasia que o poeta, a partir da universalidade transparente e abstrata dos conceitos, consegue combiná-los em vista de atingir de forma precipitada a representação intuitiva. Porém, a fantasia não é signo de gênio, segundo Schopenhauer, pois "pessoas completamente desprovidas de gênio podem possuir bastante fantasia"13. Além disso, o filósofo alemão afirma que a apreensão da Ideia pelo gênio ocorre "não por um instante, mas de modo duradouro e com tanta clarividência quanto for preciso para reproduzir, numa arte planejada, o que foi apreendido"14. Mais adiante, o pensador defende que a fantasia coloca o gênio (poeta) na condição de, com base no que chegou à sua percepção efetiva, construir o restante (reproduzir numa arte planejada) e, consequentemente, deixar desfilar diante de si quase todas as cenas possíveis da vida.

\section{0 papel da fantasia na exposição poética}

No caso da arte poética, podemos observar que, por um lado, a fantasia se faz necessária para que os conceitos abstratos, que são seu material imediato, sejam reunidos pelo poeta de tal forma que na poesia o conceito não permaneça em sua universalidade abstrata. Por outro lado, como as palavras fazem efeito imediatamente apenas sobre a razão, e não sobre a fantasia, a maior tarefa do poeta ao expor a Ideia por meio da poesia seria a de colocar em movimento a fantasia do leitor, de acordo com o fim correspondente e mediante uma atuação indireta (pois intermediada por conceitos), "de tal maneira que ela [a fantasia] crie no ouvinte as imagens nas quais ele conhece as

\footnotetext{
${ }^{11}$ Idem, § 51, p. 280.

12 Ibidem.

13 Idem, § 36, p. 215.

${ }^{14}$ Idem, p.214.

A exposição (Darstellung) poética na metafísica do belo de Schopenhauer
} 
Ideias"15. Vale salientar aqui que se as Ideias são essencialmente intuitivas, os conceitos abstratos comunicados imediatamente por palavras na arte poética só podem permitir que o ouvinte ou o leitor intua as Ideias da vida quando, por meio de representantes desses conceitos, a fantasia dele é colocada em movimento.

O filósofo também apresenta outras observações sobre o modo com que os conceitos têm de ser reunidos para que a fantasia do ouvinte seja posta em movimento, tal como a questão do ritmo, da rima etc. Schopenhauer chega a enumerar, p. ex., quatro meios a serem utilizados pelo poeta a fim de movimentar a fantasia do leitor ou ouvinte: 1) A composição de conceitos, de modo que suas esferas se intersectem e nenhuma delas permaneça numa universalidade abstrata, mas, no lugar do conceito, apareça um representante intuitivo na fantasia do ouvinte, que é modificado pelas palavras do poeta, a depender da intenção do momento. 2) A construção intuitiva (Anschaulichmachung) do exposto, que significa dar vivacidade à exposição e à expressão. “É a condução do conceito à intuição, que é alcançado pelo fato de o poeta não ser frio e vago ao narrar as ocorrências, mas sim colori-las, descrevendo-as de modo bastante determinado"16. 3) A inerência e a propriedade da expressão, proprietas verborum, que significa o acerto na designação, pela qual o poeta tem de apreender o específico, "a essência íntima da coisa, exprimindo-a sem interferência do casual e do inessencial"17. 4) A brevidade da expressão: "A expressão pormenorizada é sempre ruim: na poesia ela suprime todo efeito. A multidão de conceitos acompanhada por muitas palavras nos detém fixamente no mero pensamento e não permite alcançar a intuição"18.

Desse modo, atentemos para o seguinte: as observações de Schopenhauer sobre os meios a serem utilizados pelo poeta a fim de movimentar a fantasia do leitor ou ouvinte parecem estar em sintonia com o que lemos no $§ 37$ do Tomo I de $O$ mundo, ocasião em que o filósofo diferencia "dom do gênio" de "técnica da arte":

0 artista nos deixa olhar com seus olhos para o mundo. Que ele possua tais olhos, a desvelar-lhe o essencial das coisas, independentemente de suas relações, eis aí precisamente o dom do gênio, o que lhe é inato; que ele esteja em condições de também nos emprestar esse dom, como se

${ }^{15}$ SCHOPENHAUER, A. MB, p. 193-194.

${ }^{16}$ Idem, p. 195.

17 Idem, p. 199.

18 Idem, p. 201.

A exposição (Darstellung) poética na metafísica do belo de Schopenhauer 
pusesse em nós os seus olhos, eis aí o adquirido, a técnica da $\operatorname{arte}^{19}$.

Esta passagem permite-nos entender que a aquisição da técnica é condição indispensável para que o gênio consiga comunicar o conteúdo que desvelou no acesso ao essencial das coisas. Nesse sentido, algumas das características que diferenciam a poesia das demais artes, notadamente no quesito exposição, podem ser notadas a partir do tipo de abordagem feita do assunto no Capítulo 37, desta vez do Tomo II de $O$ mundo, onde o pensador, já no título, trata a poesia a partir de uma estética (e não de uma metafísica!), ou seja, pautando-a mais em questões sobre meios e formas pelos quais a poesia seria comunicada ou expressa e nem tanto a partir de noções do núcleo metafísico de sua teoria do belo. Neste capítulo, a poesia é definida como "a arte de pôr em jogo a imaginação mediante palavras"20 e o filósofo se ocupa logo no início com o modo pelo qual o poeta conseguiria lograr isso, citando, para argumentar, uma carta de Wieland a Merk, na qual o primeiro confessa ter passado dois dias ocupado com uma única estrofe $^{21}$. Trata-se da preocupação que sempre teria de acompanhar o poeta sobre o detalhe do termo escolhido para expor o intuído, o que nos sugere que, senão a intuição estética, ao menos a exposição artística em Schopenhauer consiste num processo que precisa submeter o que fora intuído de forma límpida e imediata ao mediato e deliberado racionalmente ${ }^{22}$.

Segundo Schopenhauer, cabe ao poeta fazer o ouvinte intuir as Ideias da vida de forma objetiva e imediata; e o objeto da arte poética é definido como "a manifestação da Ideia correspondente ao grau mais elevado de objetivação da vontade, a exposição dos seres humanos na série concatenada de seus esforços e ações"23. Ou seja, não se trata de expor um objeto estático e constante, como fazem a pintura e a escultura. 0 tema

${ }^{19}$ SCHOPENHAUER, A. MVR I. § 37, p. 225, grifos nossos.

${ }^{20}$ SCHOPENHAUER, A. MVR II. Cap. 37, p. 509.

${ }^{21} 0$ trecho da carta citada por Schopenhauer é o seguinte: "Passei dois dias ocupado com uma única estrofe, em que no fundo o tema estava numa única palavra que eu necessitava e não conseguia encontrar. Virava e revirava a coisa de todos os lados em meu cérebro; porque, quando se trata de uma descrição pictórica, de maneira naturalmente solícita gosto também de trazer diante do meu leitor a mesma visão determinada que pairava diante de mim, e com frequência, ut nosti, tudo depende de um único instante ou traço ou reflexo" (WIELAND. Briefe an Merk, editadas por Wagner, 1835, p. 193, apud SCHOPENHAUER, A. MVR II. Cap. 37, p. 509).

${ }^{22}$ Sobre a capacidade do artista em apreender ou elaborar as coisas de maneira objetiva e, assim apresentá-las em suas obras de modo que no observador ou leitor a intuição das Ideias seja ocasionada, cf. KOSSLER, Matthias. Sobre o papel do discernimento [Besonnenheit] na estética de Arthur Schopenhauer, p. 22.

${ }^{23}$ SCHOPENHAUER, A. MVR I, § 51, p. 282.

A exposição (Darstellung) poética na metafísica do belo de Schopenhauer 
principal e a tarefa da arte poética seria a exposição da Ideia de humanidade, apresentando "o ser humano [...] na medida em que [este] se exprime não apenas mediante a simples figura e a expressão do rosto, mas por meio de uma cadeia de ações acompanhadas por pensamentos e afetos" 24 , o que confere à poesia o status de rainha das artes.

Um desses aspectos, que destaca particularidades da poesia diante das outras artes, aparece no $\S 50$ de $O$ mundo (Tomo I), onde Schopenhauer explica sua recusa do conceito em artes mediante a recusa da alegoria nas artes plásticas. A alegoria, uma obra de arte que envia a algo outro que aquilo que expõe - algo outro que, por sua vez, revelase necessariamente uma abstração - impediria a genuína tarefa da obra de arte, que é a de expor ou transmitir a Ideia de forma intuitiva, límpida e sem mediações. A arte alegórica impossibilita este intento pelo fato de, no caso de uma pintura, p. ex., o seu significado ter de ser procurado para além da exposição pictural. Em se tratando da poesia, porém, o pensador observa como as coisas estão numa relação inversa:

A alegoria tem com a poesia uma relação completamente diferente da que tem com a arte plástica: se nesta é repreensível, naquela é admissível e mesmo bastante útil. Pois na arte plástica a alegoria leva do intuitivo dado, justamente o objeto de toda arte, para os pensamentos abstratos; na poesia a relação é inversa: aqui o que é dado imediatamente por palavras é o conceito, e o próximo passo é sempre ir deste ao intuitivo, cuja exposição tem de ser sempre executada pela fantasia do ouvinte 25 .

Em outras palavras, se nas artes plásticas a alegoria transporta do intuível, que é dado, para significados abstratos, na poesia, ao contrário, o que é dado imediatamente em palavras é o conceito, e o próximo passo seria, sempre, ir do conceito em direção ao intuível, numa exposição e fruição pela qual a fantasia do ouvinte ou leitor tem de ser movimentada.

Diante disso, podemos afirmar, para concluir, que se a Ideia é e permanece ${ }^{24}$ Ibidem. Schopenhauer observa que a Ideia de humanidade pode ser exposta basicamente de duas
maneiras pela poesia, o que serve como parâmetro para diferenciar os gêneros poéticos: "Ou aquilo a ser
exposto é também simultaneamente o expositor, o que ocorre na poesia lírica - na canção propriamente
dita -, na qual o poeta apenas intui vivamente o seu estado e o descreve, com o que, mediante o tema, uma
certa subjetividade é própria a esse gênero; ou a exposição é inteiramente diferente do expositor, como
nos demais gêneros, nos quais o expositor oculta-se em maior ou menor grau por trás do exposto, ao fim
desaparecendo por completo" (idem, p. 287-288). Por "demais gêneros", o filósofo está referindo à
romança, ao romance, à epopeia e ao drama.

25 SCHOPENHAUER, A. MVR I, § 50, p. 277.

A exposição (Darstellung) poética na metafísica do belo de Schopenhauer 
intuitiva, o poeta não tem consciência in abstracto da intenção e do fim de sua obra, ou seja, ele tem diante de si apenas uma Ideia, não um conceito. Por isso mesmo, segundo Schopenhauer, ele não poderia fazer um relato da sua atividade, pois trabalharia com o simples sentimento, de maneira instintiva e inconscientemente ${ }^{26}$. 0 que mais nos interessa destacar, então, é que a exposição da Ideia apreendida pelo poeta se daria a partir de uma combinação de técnica e de fantasia, o que possibilitaria, como asseverou o próprio filósofo citando o grande Goethe, "fixar em pensamentos [ou, diríamos aqui, em poemas] duradouros o que oscila na aparência"27.

\section{Referências bibliográficas}

BARBOZA, Jair. A metafísica do belo de Arthur Schopenhauer. São Paulo: Humanitas - FFLCH/USP, 2001.

Infinitude subjetiva e estética: natureza e arte em Schelling e Schopenhauer. São Paulo: Unesp, 2005.

. Os pintores de Schopenhauer e Nietzsche. Cadernos Nietzsche. São Paulo, Vol. 31, 2012, pp. 189-207.

BRUM, José Thomaz. O pessimismo e suas vontades - Schopenhauer e Nietzsche. Rio de Janeiro: Rocco Editora, 1998.

CACCIOLA, Maria Lúcia. Schopenhauer e a questão do dogmatismo. São Paulo: Edusp, 1994.

. Sobre o gênio na estética de Schopenhauer. Ethic@ (UFSC). Florianópolis, Vol. 11, N. 2, 2011, pp. 31-42.

. O conceito de interesse. Cadernos de Filosofia Alemã. São Paulo, Vol. 5, 1999, pp. 5-15.

. 0 intuitivo e o abstrato na filosofia de Schopenhauer. In: SILVA, João Carlos Salles Pires da (Org.). Schopenhauer e o idealismo alemão. Salvador: Quarteto, 2004, pp 169-186.

. Schopenhauer e Mondrian. Doispontos. Curitiba - São Carlos, Vol. 11, N. 1, 2014, pp. 91-103.

KOSSLER, Matthias. Sobre o papel do discernimento [Besonnenheit] na estética de Arthur Schopenhauer. In: DEBONA, Vilmar; FONSECA, Eduardo Ribeiro da; MATTOS, Fernando Costa [et al.] (Orgs.). Dogmatismo e antidogmatismo: filosofia crítica, vontade e liberdade - Uma homenagem a Maria Lúcia Mello e Oliveira Cacciola. Curitiba: Editora UFPR, 2015, pp. 19-36.

MAIA-FLICKINGER, Muriel. A outra face do nada. Sobre o conhecimento metafísico na estética de Arthur Schopenhauer. Petrópolis: Vozes, 1991.

MANN, Thomas. O pensamento vivo de Schopenhauer. Trad. Pedro Ferraz do Amaral. São Paulo: Livraria Martins Editora, 1960.

SCHOPENHAUER, Arthur. Sämtliche Werke. Edição hitórico-crítica de Paul Deussen. Vol. 16. München: Piper Verlag, 1911-1941. In: "Schopenhauer im Kontext III" - Werke, Vorlesungen, Nachlass und Briefwechsel auf CD-ROM (Release 1/2008).

26 Idem, § 49, p. 277.

27 Idem, § 36, p. 214.

A exposição (Darstellung) poética na metafísica do belo de Schopenhauer 
. O mundo como vontade e como representação. Tomo I. $2^{\text {a }}$ ed. Trad. Jair Barboza. São Paulo: UNESP, 2015.

. O mundo como vontade e como representação. Tomo II (Suplementos). Trad. Jair Barboza. São Paulo: UNESP, 2015.

. Metafísica do belo. Trad. Jair Barboza. São Paulo: UNESP, 2003.

. Sobre a filosofia e seu método [parte de Parerga e paralipomena]. Organização e tradução de Flamarion Caldeira Ramos. São Paulo: Hedra, 2010.

Parerga e paralipomena. Tomo II. $3^{\text {a }}$ ed. A cura di Mario Carpitella. Traduzioni di Mazzino Montinari e di Eva A. Kuhn. Milano: Adelphi, 2007.

ROSENFELD, Anatol. Influências estéticas de Schopenhauer. In: Texto/Contexto I. São Paulo: Perspectiva, 2009, pp. 173-185.

Recebido: 05/04/17

Received: 04/05/17

Aprovado: $15 / 07 / 17$

Approved: 07/15/17 